\title{
The Improvement of Learners' Proficiency in English Second Language Through Remedial Work
}

\author{
Linake Manthekeleng Agnes, Moyo Nguni Thembekile, Makeleni Sive \\ Department of Education, University of Fort Hare, East London, South Africa \\ Email address: \\ mlinake@ufh.ac.za (L. M. Agnes), moyothembekile8@gmail.com (M. N. Thembekile), SIMakeleni@ufh.ac.za (M. Sive)
}

\section{To cite this article:}

Linake Manthekeleng Agnes, Moyo Nguni Thembekile, Makeleni Sive. The Improvement of Learners' Proficiency in English Second Language Through Remedial Work. Arabic Language, Literature \& Culture. Vol. 6, No. 1, 2021, pp. 1-11. doi: 10.11648/j.allc.20210601.11

Received: October 1, 2020; Accepted: November 2, 2020; Published: January 4, 2021

\begin{abstract}
This study focused on the remedial program on learners' proficiency in English second language, which was conducted in two township schools in King William's Town District. This explored the remedial program that could be used to help learners become proficient readers who could be able to read for meaning and comprehend. A case study research design was used where two township schools were sampled. A qualitative approach located in the interpretive paradigm was used to carry out the study. The purposive and the sampling procedure were used to solicit information from principals, educators, and learners. The data collected through interviews and observations. Its focus was to establish a remedial program to improve learners' proficiency in English second language. Thus, the findings revealed that a remedial program goes a long way in improving learners' proficiency in English Second Language. "Cheng and Slavin" [11] found out that the remedial programmes showed positive results had in common and the use of extensive professional development, coaching, and cooperative learning. In this view, the English second language learners could benefit more from proficient personnel in the language. The study recommends that there should be provision for trained remedial educators in all schools to attend to the individual needs of learners appropriately. Besides, the study should explore the models, methods, and theories on reading, the strategies that could be used to boost or alleviate the learner's proficiency in English second language.
\end{abstract}

Keywords: Remedial Program, English Second Language Proficiency, Reading Comprehension, Qualitative Research

\section{Introduction}

The second language is the main challenge to all the learners as it is complex and a difficult skill to acquire easily. Numerous studies have been conducted on a second language, in particular, English as a medium of instructions that affect learners' performance at school due to a lack of learners' proficiency. Hence, this paper focused more on the remedial work done to improve the learners' proficiency in English as their second language and the medium of instructions. Conversely, English as a second language refers to specialized approaches to language teaching designed for those whose primary language is not English. This means that these learners get affected and struggle with using a strategic approach to learning and accomplishing assignments. Some of them perform below their peers academically and this demotivates them. In this view, the researcher decided to implement the remedial program to assist the learners who are always left behind.
Additionally, the researchers were challenged to explore a remedial program on the improvement of learners' proficiency in English as a second language at sixth grade low achievers in King William's Town Education District schools. Thus, the researchers chose to remediate grade six learners to ascertain profound improvements in learner's performance at the intermediate phase, before learner deficits have become too high and have fallen too far behind.

"Van der Berg, Wills, Selkirk, Adams, \& Van Wyk" [62] concur with the researchers' intentions by stating that the remediation is most possible and most cost-effective when children are still young and to avoid repeated retention which might cause learners to drop out of school. Besides, the researchers chose the township schools where the quality of education is poor as in rural areas. "Maree" [31] asserts that the quality of education remains poor in these deprived socio-economic contexts. On the other hand, "Spaull and Kotze" [53] argue that the uneven functioning of the South African schooling system further widens learning gaps. In 
this regard, the researcher was trying to explore how a remedial program could close the gap in the schooling system.

Based on the arguments above, remediation is a type of instruction through which errors are corrected and the repetition of earlier flows prevented. Through remediation, learners are cured against a defect "Reuters" [52]. Remedial teaching is regarded as a purposeful effect to reinforce the forgotten concept to upgrade underachievers by remedying their errors "Reuters" [52]. He further avers that remediation offers interdisciplinary articles that bridge the gap between theory and practice involving the education of individuals for whom typical instruction is not effective. It also reinforces the parts or structures that are forgotten due to disuse.

Simultaneously, the researchers decided to assist the learners to be independent as they are close to high school whereby they are expected to work individually with more understanding. At this level, learners must be proficient in the language of learning and teaching to become competent during the academic work. Thus, the learners who have not reached proficiency in English struggle to learn grade-level content, take longer to graduate, and even at lower rates than English proficient peers graduate "Kim and Sin [24]. 'English language proficiency" (ELP) is English proficiency in four areas such as speaking, listening, reading, and writing English Language Proficiency is further regarded as an indicator measure of English Language (EL) ability to use the English language for communication and academic work. In this regard, this indicator is required to be included in the accountability system.

Thus, the ELP indicator was based on the results of an English proficiency assessment designed for students who are learning English as a second language. This was aligned with English-as-a-second-language standards. "Taylor and Coetzee" [60] echo this by highlighting that several types of research have demonstrated that most South African children in poor communities have accumulated large deficits in English proficiency at grade fourth. In this view, for the learners to be proficient and productive, they need various opportunities to interact in social and academic situations. Thus, effective educators encourage their learners' participation in classroom discussions, welcome their contributions, and motivate them by such practices "Cazden [7]".

\section{Review of Literature}

The literature review acts as the foundation of the study hence each scholar has to fully engage with it beforehand to compare and contrast issues that are related to the current study. It further assists the researchers to identify the gap that needs to be researched. In this view, both the literature and theoretical framework are intrinsically linked. Thus, this study is guided by Vygotsky's social constructivism theory for logically developing and understanding the different interconnected parts of literature. "Mitchel and Myles" [37] defines social constructivism as the material world shapes and these shapes by human actions and interaction dependent on the dynamic normative and epistemic interpretation of the material world.

Both literature and theory adopted focused on a remedial program in learners' proficiency in English second language at township schools. According to "Oliver" [47] highlights that new studies should not be isolated, but exist within academic traditions, guided by similar studies. Thus, "Usherwood" [64] posits that no research is undertaken in isolation from the work of others. In this regard, the researchers are better prepared to address the problem with deeper insight and complete knowledge. In this section, the researchers compared and contrasted a remedial program on learners' proficiency in English Second Language global, national, and in the South African context. This approach helped the researcher to identify the current approaches used globally and to detect what is not done and how that could be done in South Africa. Simultaneously, the social constructivist theory by Vygotsky was interchangeably used with the relevant literature to address the problem identified in this research as highlighted earlier on.

\subsection{The Importance of the Background and Culture of the Learner}

The learner as a member of a particular culture inherits historical developments and symbol systems, such as language, logic, and mathematical systems. These are learned throughout the learner's life. In addition, the learner's cultural background can provide the necessary context for effective mediation "Nieman and Monyai" [43]. This also stresses the importance of the nature of the learner's social interaction with knowledgeable members of society. This means that there are people who are more knowledgeable within society than social interaction. It is impossible to acquire the social meaning of important symbol systems and learn how to utilize them. Thus, learners develop their thinking abilities by interacting with other learners, adults, and the physical world. "Nieman and Monyai "[43]. concur with this by explaining that the educator broadens the learner's environment and connects it with previous experiences and cultural backgrounds in this mediation process. In this way, learners can link divergent aspects of an experience together in a meaningful way.

\subsection{Implications of Theory on Remediation and Second Language Teaching}

In second language (L2) classes, the theory asserts that learning is a collaborative achievement and not an isolated individual's effort, where the learner works unassisted and unmediated. The theory emphasizes that during instruction, awareness of the structure and function of language is developed by using it socially. In addition, second language learners need coaching and explicit instruction to appropriate the fundamental skills of L2 "Vygotsky" [63]. "Leki" [29] claims that a lack of such skills can hinder their progress and improvement as competent readers, writers, and language 
users. The importance of meaning construction in the act of learning is fundamental in L2 classroom interactions. The rise of approaches such as integrative teaching of reading and writing is nothing but a recognition of the importance of meaningful interaction of L2 students with texts in classrooms.

"Zimmerman and Smit [66]" argues that enhancing learners' competency in L2 should not be seen to be located in mastering skills. These results to too much concentration on skills could deprive learners of engaging with what he refers to as aspects of literacy such as meaning construction, competency, fluency, and flexibility with dealing with texts as readers and writers. The theory regards instruction as crucial to L2 development in the classroom. Instruction should be geared to the zone of proximal development that is beyond the learner's actual development level.

There is limited literature that talks about effective remediation programs in developing countries. Thus, a small but growing body of literature addresses interventions for "learners who struggle academically" Richards - Tutor et. al, [53]" and only a handful of studies are in lower - middle income and low-income countries that provide an important base on which to build policy and program insights. This is in line with a review of studies on the effectiveness of remedial programs for English language learners. "Cheng and Slavin" [11] found out that programs that showed consistently positive results had in common the use of extensive professional development, coaching, and cooperative learning. Respectively speaking, the theoretical framework and the literature are intrinsically linked as they both used as a guide for logically developing and understanding the different.

Piaget's cognitive developmental theory proposes that language is but one of several varying skills and appropriate language development depends on general cognitive maturity. This observation is related to Piaget's stages of cognitive development. The reasoning behind this view is based on the rationale that only when learners reach a particular level of cognitive maturity where they need symbols to represent things, do they need to use words and develops language. The cognitive ability then interacts with the milieu demands and language experience to produce progressively more mature language proficiency "Mogi and Tokor" [38].

In addition, the social interactionist theory postulates that language development is dependent on children's social contact and communication with other people. Such language socialization entails direct language instruction as well as more indirect ways of expressing proper language interaction. This is a particular form of speech used when conversing with young children that vary from a normal speech in tone, pitch and includes more questions than when directed at adults. Learners then internalize the language, whereby they first use words in their dealings with other people and then steadily integrates it into their daily thought patterns. The language also has a functional aspect for the human species. Through language, learners increase their knowledge, procure meaningful interpersonal relationships, manage their behavior, and manipulate the behavior of other people "Mcdevitt et al [34], "Littlefield \& Cook" [30].

Most township learners speak only their home language with parents and siblings. Out of a group of two hundred Grade 6 learners (at the two township schools understudy), only three learners spoke English as a home language. Generally, township learners have difficulty in understanding more advanced and abstract terms and phrases. This means that an educator can never assume that learners understand all words in written text because township learners display several difficulties in verbal and written English communication. They often confuse tenses and gender, and sometimes they refer boys to as "she" and vice versa. They also struggle with the pronunciation of several English words Sometimes parents of the ESL learners are not proficient in English and are unable to assist these learners with homework tasks.

In general, instructions have to be repeated and explained to quite several learners during a lesson period. The more confident learners tend to raise their hands, while the more timid learners tend to walk up to her desk to enquire. Some learners are unsure but do not ask for help. They turn up the next day without homework. Very often, the researchers have to rely on code-switching, where he translates instructions in the home language of a learner who has difficulty understanding instructions in English Second Language. Long or complicated tasks usually have to be explained further in groups with the assistance of their peers to cater for the remedial learners who would otherwise get confused.

\subsection{Remedial Programme on the Improvement of Learners' Proficiency in English Second Language}

Sharples, Slavin, and Chambers [9] aver that practicing reading at an early age minimizes the percentage of low achievers, that is, the earlier learners read the fewer the number of low achievers. A supplemental reading program will be adopted as the remedial reading program for the improvement of English proficiency as a second language. This program consists of rereading unfamiliar text until a satisfactory level of fluency is reached. "Lesaux" [27] postulates that reading is a dynamic and multifaceted process that requires continued development if learners are to keep pace with the increasing demands of school texts and tasks. However, learners from Grade 4 onwards are reading to learn. This implies that these learners begin to reach higher levels of reading competencies. These levels include reading for meaning, interpretive reading, inferential reading, analytical reading, and critical reading "Hungi, Makuwa, Ross, Saito, Dolata, Cappelle, Paviot, \& Vellien” [21].

Additionally, it is important that learners have access to programs that meet their requirements and that remedial teaching has content that helps them to "consolidate basic knowledge, master their learning strategies, strengthen their confidence and increase the effectiveness of their learning" (Cheng Learners are better equipped with basic skills to improve their communication and writing skills. Typically, remedial learners are not struggling because of their 
intellectual abilities but instead because they are struggling with one subject area like reading, writing, or mathematics. This implies that learners should be taught how to create, adjust their strategies, and assimilate learning activities into their world. When learners perform an activity, they can do some part of it on their own, but not all.

Basic skills in the use of English as a second language can only be instilled in the minds of learners if they are exposed to prolonged periods of studying the language. Therefore, both educators and learners should be willing to go the extra mile in improving learners' language proficiency. It is evident from studies carried out on learners receiving remedial teaching that they had better motivational levels and were more likely to succeed academically than those who did not take advantage of such an intervention "Jadal" [22]. In this way, the researcher is hoping for an improvement in the learner's proficiency outcomes by engaging the low achievers in remediation.

\subsection{Lack of English Proficiency Affects the Learners' Performance in their Examinations}

When learners' proficiency in the English language is high, it will improve the academic performance of such learners positively. Nevertheless, where proficiency in English is lacking in any academic setting, it will lower the academic performance of such learners. To support this, "Sclebusch" [57] states that the high failure rate at schools is caused by, among other factors, a lack of English proficiency of learners before entering the senior phase (Grade 7-9). Alarmingly, in the Eastern Cape, only 20 percent of Grade 2 pupils from the 2001 cohort went on to pass the NSC exam in 2011. This implies that because learners normally fail to understand the target language in the lower grades, they are unlikely to master that language at secondary and university levels. Hence, "McDonough, Shaw, and Masuhara" [33] maintain that educators and learners should use the second language rather than the first language in the classrooms. Educators may, therefore, need specific teaching strategies to help learners with poor English proficiency to perform better in English as a subject.

Thus, the research observed revealed that the performance of learners in Mathematics examinations at Senior Secondary School Certificate Examination (SSCE) is poor due to reading ability. This indicates that lack of or low proficiency in the English Language is one of the factors contributing to poor academic performance. Although reading fluency and comprehension are important skills to acquire, as they are essential skills for success in both schools and later in life, many children do not acquire the necessary skills for achieving proficiency. According to a recent study, $40 \%$ of fourth-graders do not have the skills and knowledge to adequately perform the necessary grade-level work "Bursuck [6]. Similarly, "Calhoon" [8] found 59\% of fourth-grade learners are performing below a basic literacy level on standardized reading tests. The research findings of two tertiary institutions in Oman show a strong, positive relationship between English Language performance and academic achievement "Roche and Harrington"[54]. Therefore, the researcher finds it important to ensure English proficiency at the primary level as it affects learners' performance at higher institutions and in every sphere of life.

"Mullis and Martin" [41] highlight the pre-PIRLS showed that Grade 4 pupils from rural areas and townships are two to two and a half years behind urban children in reading "Howie $\&$ van Staden" [20]. Educators should focus their teaching on meaning construction where learners will be able to assimilate, internalize, and integrate the new information with the information they already possess. "Howie \& van Staden [20] further indicate the importance of the meaning construction and fluency in L2 classrooms when he suggested the simultaneous dual focus on form and accuracy together with meaning and fluency in L2 classroom as the best way of enhancing learners' level of proficiency. Vygotsky encourages educators not to concentrate too much on teaching concrete facts, but to push their learners into an abstract world as a means of assisting them to develop multiple skills that will enable them to deal with complex learning tasks. In this view, learners who are exposed to rich language environments where adults assist in the construction of language, develop better language skills as compared to those who do not have a rich social context opportunity.

ESL learners often experience difficulties regarding assessment when they are expected to write academically, using the correct terminology about a specific subject, they are assessed in "Nel \& Booysen" [44]. They further suggest that to accommodate limited language proficiency and provide ESL learners' opportunities to demonstrate mastery of knowledge, it is important to use various kinds of assessment strategies, such as practical application, besides written and oral tasks. Learners can be encouraged to speak in the second language all the time at school to familiarise themselves with the language to improve their proficiency in the target language.

\subsection{Learners Attitude towards English Second Language}

Attitudes toward the language are of particular importance because the greater the learner's interest in the language and its culture, the easier learning will be "Mishan" [36]. The attitude is linked to motivation as a positive attitude will imply motivation to act positively because what and how much is learned is influenced by the learner's motivation to act. "Gardner \& MacIntyre" [17] quoted in "Mitchell \& Myles" [37] explain motivation as the desire to reach a goal, the effort devoted towards the goal, and the satisfaction obtained in doing the activities needed to reach the goal. Conversely, low achievers can make better relationships with their peers and improve their attitude towards learning, as remedial teaching helps learners find a match between their characteristics and the school environment so that their academic and behavior demands can be met" "Cheng" [10].

"Nel" [45] further explains that ESL learners struggle with the fluency of speech as the ability to decode words in a second language is often hampered. Learning to read a 
transparent orthography is simpler because there is a stronger relationship between each letter and its corresponding sound than in a more opaque orthography. Some linguistic units are more important in some languages than others are whilst in English.

"Broom and Le Ro Swartz, \& Swart" [4] found that the influence of a different grammatical, morphological and semantic structure of an African Language might cause ESL learners to have lower language proficiency levels in English, resulting in learners' poor application of skills required for reading.

\subsection{Mediation and the Importance of Language}

The emphasis here is on the learner as an active "maker of meanings". The role of the educator is to enter into a dialogue with the learner, in an attempt to understand the meaning that the learners attached to the material to be learned and to help them then to refine the understanding until it corresponds with understanding the educator, as the more knowledgeable one in this particular situation, holds "Raymond and Atherton" [51]. The learner is involved in making sense as an active individual, the role of the active environment, as well as the culture and background of the learner, cannot be denied to play a role in the process of finding new meaning. "Rajabi and Ketabi" [50] affirm that learners who are said to have acquired a language are those who can align themselves with the culture of the target language.

\subsection{The Development of Language Skills in Grade 6 Learners}

According to "Phajane \& Mokhele" [49] at the age of twelve, a learner's receptive vocabulary is approximately 50 000 words and it increases to about 80000 words by secondary school level. Thus, an increase in cognitive ability enables learners to use more abstract words and phrases in their communication. Hence, different meanings associated with intonation remain a challenge for remedial learners. Thus, learners struggle with passive full sentences right up to into adolescence stage. Additionally, pragmatic language aptitude continues to develop, enabling learners to correct ambiguity in their language use and that of others. This makes learners of this age understand the social rules of communication and they know when it is acceptable to adhere to or overstep social boundaries, such as repeating what someone said to show either interest or disrespect "Littlefield \& Cook" [30].

Simultaneously, learners in the intermediate phase show progressive understanding of chronological words such as "before" and "after", as well as expressions of comparison such as "smaller than" or "as cold as" than those at the foundation phase. Respectively speaking, they still need formal instruction in irregular forms of verbs and adjectives especially those in the past tense, such as "lie" and "lay", as they tend to have difficulty in discerning which of these should be "lay" and "laid" in the past tense to guide them.
Hence, it is common for learners in this phase to interpret messages literally. Thus, pronunciation dexterity is achieved at about age eight. They take a listener's knowledge and viewpoints into consideration during conversations. In the intermediate phase, learners can conduct prolonged conversations about concrete issues. They further display linguistic creativity and are skilled in word games and rhymes "Mcdevitt and Ormrod" [34].

\section{Theoretical Framework}

The theoretical framework is a guide on which to build and support all the researchers' studies. It also provides the structure to define how one would philosophically, epistemologically, methodologically, and analytically approach the dissertation or thesis as a whole. Thus, "Kristian"[25] defines a theoretical framework as "a structure that guides research by relying on a formal theory....constructed by using an established, coherent explanation of certain phenomena and relationships". This means that the theoretical framework consists of the selected theory that undergirds the researchers" thinking about how they understand and plan to research their topics. It is further measured as the concepts and definitions from those theories relevant to the topics. Thus, the theoretical framework of this study is positioned in the field of Education and anchored in literature based on the research topic." Henning, Van Rensburg \& Smit" [19] indicate that a theoretical framework facilitates the dialogue between the literature and research study. In this regard, the research process involved continuous contemplative consideration of interrelated main concepts of this research study. "Henning" [19] further states that a theoretical framework leads to a specific conceptual framework, which, could be described as an alignment of the key concepts of the study.

Based on the discussion above, a theoretical framework synthesizes existing theories, related concepts, and empirical research, to develop a function for new theory development "Grant \& Osanloo" [18]. It also informs the research questions and methodology and helps to justify the research problem. In addition, a theoretical framework is derived from an existing theory in the literature that has already been tested and validated by others and is considered a generally accepted theory in the scholarly literature. For this s, a social constructivism theoretical framework was adopted as it was regarded as appropriate and relevant to the remedial program that deals with learners' language challenges. Vygotsky's theory sees the educator as the mediator in the construction of learning by the remedial learners. Thus, an appropriate context should be set up in the manner that the learners would become engaged in activities that interest and encourage them during the learning process. In the context of this study where the focus is on an ESL classroom, logical thought must be expressed through language practices as part of classroom activities.

In this regard, the learners must be encouraged to ask questions and explore all relevant topics freely "Vygotsky" 
[63] There are four key concepts derived from Vygotsky's theory that apply to this study "Monteiths., Brunner, Djagaeva, Bielecki, Deutsch, and Saxton" [39]. A Social Context; Zone of Proximal Development (ZPD); Scaffolding and; Cognitive apprenticeship.

\section{Research Methodology}

The research approach adopted in this paper was qualitative, in which the interpretive paradigm was used. According to "Myers"[42, qualitative research is designed to help researchers understand people and the social and cultural contexts within which they live. Thus, the researcher is considered the primary instrument of data collection and analysis. The purposive and the sampling procedure were used to solicit information from principals, educators, and learners. Semi-structured interviews and observation tools were used to collect data. A case study research design was also used in this paper where the focus was on schools based in King Williams Town. "Schofield" [55] describes sampling as a method that considers whoever is available and willing to take part in the study as long as they fulfill the required attributes. This study moved within the parameters of qualitative research in that it sought to determine the improvement of learners' in second language English proficiency through remedial work that teachers used to assist the learners' performance academically.

In this regard, this paper selected a sample of two educators and two principals from each school. The collected information on the experiences of the participants primarily through in-depth interviews and observation. "Johnson and Christensen" [23] emphasize that qualitative interviews can be used to obtain in-depth information about a participant's thoughts, beliefs, knowledge, reasoning, motivations, and feelings about a topic. "Saez" [56] mentions that in semistructured interviews, the entire process is improvised and conversational, while key points and answers are recorded on a form designed to evaluate and sort answers. This gives the person being interviewed a chance to give a lot of good information while making the entire process seem more like a normal conversation than a question session. Conversely, the researchers used the semi-structured one-to-one interview. This implies that semi-structured interviews, gave the researchers the freedom to decide the structure and content of questions to be asked of participants and questioning technique and sequencing of questions. During the interviews, the researchers designed semi-structured interview questions for both principals and educators to get accurate and in-depth information. Additionally, researchers used semi-structured interviews to gain a detailed picture of a participant's beliefs about, or perceptions or accounts of, a particular topic.

Simultesoulsy, the interviews were tape-recorded and notes were taken as a back-up then transcription of data was made to ensure accurate data. In this view, the interviews allowed the participants to provide meaningful or important information about the subject that was under discussion to him or her using his or her own words rather than being restricted to predetermined categories. Certainly, participants asked for clarification of certain statements or questions during the interview process, something that could not have been possible if a questionnaire was the sole research instrument. "Maree" [32] supports interviews by saying that they provide high credibility and face validity, and make intuitive sense to lay audiences. The type of interviews used in this study was semi-structured. In addition, they enable participants to project their ways of defining the world "Johnson and Christensen"[23]. They permit flexibility rather than fixity of sequence of discussions and enable participants to raise and pursue issues and matters that might not have been included in structured questions "Denzin and Lincolin"[13]. During semi-structured interviews, the researchers asked informants a set of similar questions. "Mertens'[35] agrees to this by indicating that semistructured interviews are based on an interview guide that is a list of questions and topics that have to be covered. In this regard, the interviewer covers each topic by asking one or more questions and using a variety of techniques to probe and decide when the conversation on a topic has satisfied the research objectives.

\section{Findings and Discussion}

This section presents and discusses the data obtained from two selected township primary schools in King William's Town Education District that formed the sample of this research. In this paper, the data was collected through semistructured individual interviews and observation only. Pseudo names, considering the principle of anonymity, have been used to profile the schools as well as the participants. During data collection, four participants were interviewed in total that is one principal and one teacher from each school since the focus was only on two schools. Consequently, the participants were interviewed to produce a balanced presentation, analysis, and interpretation of data. In this regard, the data collected from these different tools would be presented and analyzed below. The transcripts were studied and the themes were identified, analyzed, and interpreted. Thus, the data would be presented accordingly per the tools used and supported with verbatim where is necessary. According to "Flick" [16], this is necessary in a case study as part of triangulation as the intention is to answer the research questions posed, to come up with the assessment model for identifying remedial learners and assist accordingly.

\section{Data Presentation}

This section focused on the improvement of learners' in second language English proficiency through remedial work. Additionally, the assessment instruments used in selecting learners for remediation and the effectiveness of educators' views in identifying learners for this intervention program would be also presented. In this view, the section that follows presents the participants' views and responses during the interview sessions and observations. The following 
pseudonyms for schools and all the participants were used to comply with the ethical issues. Conversely, the letters A and $B$ were used for Schools where the first school was named school A and the second one named school B. For instance, School A is a big school starting from Grade R up to Grade 12 and most of the grades have more than 60 learners. Additionally, English as a Second Language is used as a language of instruction from Grade 4 upwards. This becomes a challenge especially in grade 4 , as it is a transition from the learners' mother tongue to English as their second language. In this school, most of the staff members are Xhosa speaking as the local community is the Xhosa tribe. Similarly, school $\mathrm{B}$ is big with Grade R to Grade 12 just like School A. The school comprises of 1 principal, 3 departmental heads, 23 educators, and no trained remedial teacher. The school is located in Quintile 4, which suggests that parents are working and can afford to pay school fees. At this school, English is used as a Home Language and the school is located close to town. The township is a mixed community of Xhosa and Afrikaans speakers, which use English as a language of instruction from Grade R. In this school, IsiXhosa and Afrikaans are used as second languages. The Ghanaian EGRA study revealed that less than a third of the schools had a library (Kochetkova and "Brombacher and Beddies" [5]. This contributed to the poor reading results for learners lagging. Likewise, the educators and the principals from both schools were also given Pseudonyms as follow: School A Educator (SAE) and School B Educator (SBE), Principal in School A (PA), Principal in School B (PB). Respectively, the researchers used these outlined coding system throughout the paper for easy reference to all the participants during data presentations and discussions.

Conversely, the data and findings were put under some main themes this paper focused on. The data and findings are presented below.

\subsection{Improvement of the Learners'Second Language Proficiency through Remedial Work}

This part was to check the educators' and principals' responses towards the improvement of the learners and proficiency in English Second Language through the remedial work. In response to how the educators felt about implementing a remedial program, they seemed to be positive about remedial and strongly felt that if they were well equipped with remedial training; the positive results would be achieved in the improvement of English Second Language. Educators from both schools expressed the same sentiments that lack of resources and training made them lose confidence in themselves as they were depending on their understanding and maybe using the wrong strategies in implementing remediation." Lerner and Johns" [26] supported this by stating that repeated failures make learners more conscious of their poor performance, which ultimately results in emotional, social self-concept problems.

Moreover, the educators felt that maybe if time was allocated for remedial lessons and trained personnel assigned, remedial work would be fruitful.’'Trudell, Dowd, Piper, \&
Bloch" [61] highlighted the fact that when educators are well trained, mentored, and supported, and they could help make the difference between failure and success of learners' second language proficiency through remedial work. For example, SAE further explained:

I feel that a properly trained remedial educator would make time for individual learners and give them what they require about improving their second language English proficiency. Unfortunately, none of us educators has been trained for this.

General, the majority seemed to have the main problem with the English language as their Second language. Thus, the research findings of this study also agree with "Fleisch" [15] who states that South African studies of academic achievement find a strong and positive correlation between socio-economic background and academic performance. This shows that a full $25 \%$ of achievement is explainable in terms of the social background of learners. In addition, some studies indicate that there is a strong relationship between poverty and performance and that poverty is linked to underperformance. Respectively speaking, poverty was one factor that affected learners reading levels and indicated that some learners got exposure to reading books only at school and only got the opportunity to read at the school only as there was no library in the area and this limited the learners' exploration and reading practice. According to "Pflepson [48]", it is easier for parents to support their children in a language they are proficient in not in another language especially English as most of the parents are no educated. This contributed to the employed remediation not yielding good results compared to the one employed in school B. The lack of resources exacerbated reading difficulties for the learners.

Comparatively, in school B, English was used as a language of teaching and learning. In this regard, the majority of the learners displayed a positive attitude towards reading in English. "Davidson" [12] argued that the more time one spends during the day speaking the second language, the better he/she was going to be at it. Thus, more learners showed positive traits towards reading because they were familiar with the language. Generally, the remedial learners were not happy with participating in remediation, as they were tired from the mainstream class activities. They felt overworked and therefore develop a negative attitude towards the language. On the other hand, considering that learners' concentration span was limited, remedial learners were not given very long passages to read. Taking note that the learners dealt with were the already struggling learners therefore, whatever was given was to be short and exciting. This yielded good results in the improvement of learners' language proficiency.

Additionally, the educator shared the criterion they used when selecting learners for remediation. The educator from school A (SEA) highlighted that they identified learners according to their class tests and observation as they participated in oral activities due to large numbers of learners. Similarly, SEB said they also used the class tests for the remedial classes. For example, SEA said,

We used in-class remediation which we thought would 
benefit all the learners in the class as more intelligent learners would assist the weak ones.

SEB added,

At our school, we used the extra class remediation done after school though learners might not be able to concentrate as we were in class for the whole day.

Based on the information above provided by the educators from both schools, they used more or less the same criterion to select the learners for the remedial classes. "Asim, Kalu, Idaka, and Bassey"[1] asserted that a remedial program was to be based on the proper identification of its recipients, failure to do so might produce psychological trauma for both the learner and the parents. This implies that the class educators as they are the ones who know the learners, who need to go through this, selected the remedial learners.

Moreover, the principals from both schools supported this by highlighting that the educators are the ones accountable for the selection of the learners for the remedial classes they deal directly with. The principal from school A (PA) further added,

I only permit educators to remain behind after school to attend to the remedial learners. I also inform the parents of the learners who were identified for the remedial class to be aware that learners will remain behind for another 30 minutes after the school ended.

\subsection{The Strategies Teachers Use to Encourage Learners to Become Proficient in English as a Second Language}

In this section, the educators for both schools highlighted the strategies they are using to assist the learners to be proficient in English Second language. The results revealed that the educators from both schools encouraged the remedial learners to share ideas in their small groups although they do it differently. For instance, the educator in school B (SBE) explained,

I read the comprehension passage aloud three times while the learners are also reading silently using English as a medium of instruction and discussed it thoroughly thereafter. Later on, I encourage learners to read the passage on their own and discuss with their peers in groups, and share ideas with the rest of the class on what it is that they have understood. I found this interesting as all the learners are fully engaged and participate. I then, give them a few minutes to ask the questions and then answer the questions from the comprehension. I then, give the remedial learners extra work to do as homework to assist them to understand better while working as individuals.

In addition, school $\mathrm{A}$ Educator (SAE) reiterated and elaborated that,

I read the comprehension passage for the learners, discussed as a class, and then allow them to answer the questions in their small groups. The small group discussions instilled an interest in the learners and they were encouraged to participate. I further use the extra class remedial, which was done, after school by repeating what was done in class with the other learners to try to assist the learners lagging.
The above responses from both educators showed the determinations and keen to assist the remedial learners. This still showed that the majority of the learners are still struggling to read and cannot comprehend what they read. A predominant reason for this reading deficit was that they could not yet read words with enough fluency to facilitate comprehension and lack of knowledge of reading strategies to reduce this deficit. Hence, educators should be able to reintroduce the text once learners were taught reading comprehension strategies. In addition to the comprehension strategies taught, the learners gained greater confidence in themselves. "Ning and Zhou"[46] argued that creating a safe, non- threatening, and learner-centered environment was also important for educators to ensure that all learners had opportunities to contribute to their group as they work better with their peers. According to the "Development and UNICEF" [14], children learn to write through, amongst other things, reading with an adult, individually or in a group.

Generally, both educators showed that no new concepts were taught to remedial learners. They further showed that regardless of learner difficulties, they were able to tell that the concepts were repeated in remediation classes to build on their language proficiency.

In this regard, the educators indicated that township learners display several difficulties in verbal and written second language communication. In this regard, learners were to read the provided material three to four times to understand comprehension and be able to answer the questions as expected. This improved the learners' proficiency and understanding of the material read in English Second Language.

In school A, three learners participated actively in the reading activities. All five learners participated in the writing activities and three of them participated actively in the group activities. The two who were not active in the reading and group activities had challenges with language communication. Hence, "Shaw and Masuhara" [58] maintained that educators and learners should use the second language rather than the first language in the classrooms. Respectively, the educators were encouraged to focus their teaching on meaning construction where learners would be able to assimilate internalize and integrate the new information with the information they already possess.

Simultaneously, in school B, four learners participated in the reading activities, all the five learners participated in the writing activities and three participated in the group activities The two inactive learners lacked confidence in their language communication skills. It was the educators' responsibility to apply different strategies and methods to support the learning process for the best results. The educators were to model the correct sound and pronunciation for the learners to follow.

This means that seven learners participated in reading activities and all the 10 learners responded in the written activities. Only six of the ten learners' participated in ingroup work. This implies that learners required individual attention to participate in the activities given to them. Group work recorded the least number of participation, as the 
learners were not free to express themselves in the second language. Learners were expected to assume the leading roles in cooperative activities so that they could be of assistance to their peers.

\subsection{Responses by Teachers on Challenges Encountered in the Implementation of Remediation}

All the two principals from different schools and two participating educators from both schools in the study indicated that there is a need for further training and support to support learners who are lagging behind their peers. This was very essential, as all of them had no proper training to deal with remediation. They only depended on teaching knowledge, which might not be beneficial to remedial learners. In both School A and School B, learners showed a negative attitude towards a remedial program. Learners did not put all their concentration into the remedial program especially in School B as the activities were done after school when their peers were free to go home or went for sporting activities. In school A, learners could not concentrate much as they thought they were being overloaded with work than their peers. This means that learners are believed to have limited concentration spam. In addition, their parents' participation at home was minimal as most of them are illiterate.

Simultaneously, the educators' responses aligned to the principals' responses. With all the participating educators and principals being ESL educators, "Howie and Van Standen" [20] claim that explaining concepts to learners as well as providing the necessary support can be a challenging task for the ESL educators due to their limited language proficiency. "Nel" [45] supports the above assertion as they explain that ESL learners struggle with the fluency of speech as the ability to decode words in a second language is often hampered.

This implies that learners whose home language is different from the school language of instruction learn less "Bhattacharjea" [3]. The results of the learners' performance in comprehension varied with more learners in School B performing better than the learners from School A. In this view, learners from School A are showing more challenges in responding to the questions as they are failing to construct sentences in the target language. Some of the learners were copying the questions instead of answering the questions. In school B, the learners could at least understand the passage though they might be unable to give the correct responses, hence their performance seemed better than those from School B.

According to Jonathan Jansen "Taylor \& Coetzee" [60], the introduction of English as early as possible is ideal to become fluent in English. This might increase the learner's confidence in the second language. With fluent learners, this might also give them a positive attitude towards their reading." Bettinger and Long" [2] suggest that remediation should be timetabled for a session of an hour duration for at least two hours a week. In this view, the educators from both schools adhered to the above requirement somehow. The educator in school B conducted remediation at least 30 minutes for four days a week whereas; the educator from school A conducted it almost every day in the mainstream class. This showed the researchers that educators are trying their best to help the learners though the department is not giving them full support regarding remediation. From the educators' response, 50\% did their remediation after school. These findings were contrary to a suggestion from 'Wilkinson' [65] that in schools where the study period was offered, this should be the ideal time for remediation, as it would give the impression that the learners were being assisted during the normal learning time. However, the findings indicated that if remediation was done during the study period, the learners would not have time to do their homework, and the educators would not be able to complete their marking and preparation for the next lesson. "Mpofu" [40] revealed that the remedial education program does not cater to learners above or below a mean in a subject. A learner who is to be selected for remediation is one who is below average.

\section{Conclusion}

The findings from this paper showed that the educators took initiatives to assist the learners to improve their proficiency in English Second Language at two King William's Town township schools by providing the remedial program. Only learners who were below average were selected to be part of remediation. A systemic evaluation of language competence of intermediate phase learners in South Africa in 2005 reflected that $63 \%$ of the learners were below the required competence for their age level.

\section{Recommendations}

The Ministry of Education should supply schools with the policy on the implementation of remediation. The school heads have to make sure that every teacher has read it. Staff development can also be conducted on the subject. Comprehensive in-service training should be provided to educators to ensure that they are well equipped to conduct effective remedial programs at schools. Encourage learners to practice the reading and writing skills inside and outside the classroom, which leads to proficiency.

Universities should include a component of remedial education in the training of educators. All schools need to have a remedial educator adequately trained on learners with special educational needs to provide sufficient support systems in remedial education and learning support.

\section{References}

[1] Asim, A. E., Kalu, I. M., Idaka, I. E. and Bassey, S. W. (2011) Competency in STM. Assessment: The Case of Primary School Teachers in Cross River State, Nigeria. Nigeria: University of Calabar.

[2] Bettinger, E. P, and Long, B. T. (2008). Shape Up or Ship Out The Effect of Remediation Students at 4 Year Colleges. (No 10369) Cambridge MA: National Bureau of Economic Research. 
[3] Bhattacharjea, A. (2017). Sylvania's Indian Precursor and it is Legacy. India: University Press. DOI: 10.1007/s11151-0179588-6.

[4] Broom, B. A. (1991). Design Rationale for a Language-based Editor. Singapore: University Press.

[5] Brombacher, C, and Beddies, G. (2015). Manfred Albrecht. (2015). Structural properties of thermoelectric CoSb3 skutterudite thin films prepared by molecular beam deposition. Journal of Alloys and Compounds. 624: 216-225. DOI: 10.1016/j.jallcom.2014.11.057

[6] Bursuck, D. W. (2016). Including Students with Special Needs: A Practical Guide for Classroom Teachers (6th Edition) 6th Edition. CA: SAGA.

[7] Cazden, C. B. (2015). The Study of Classroom Discourse: Early History and Current Developments. Harvard University: SAGA.

[8] Calhoon, M. B. (2016). The effects of peer-assisted Remedial and Special Education (REM SPEC EDUC). CA: SAGE.

[9] Chambers, D. (2011). Maximizing the Impact of Systematic Reviews in Health Care Decision Making: A Systematic Scoping Review of Knowledge-Translation Resources. New York: Unversity Press.

[10] Cheng, C. M (2014). Individual differences: How remedial teaching transforms Low- achievers when learning English. Journal of Modern Education Review, 4 (11), 859-877. https://doi.org/jmer(2155-7993)/Research design:Qualitative, quantitative, and mixed methods approaches (2nd ed.). Thousand Oaks, CA: SAGE Publications 11.04.2014/001.

[11] Cheng, A, and Slavin, R. E (2016). How Methodological Features Affect Effect Sizes in Education. Hong Kong: Chinese University Press.

[12] Davidson, R. (2012). The motivation for learning a language. Modern Language Vol 5 (78): 12-28.

[13] Denzin, N. K. \& Lincolin, Y. S (Eds), (2011b). The SAGE handbook of qualitative research (4th ed.). CA: Sage, Thousand Oaks.

[14] Development and UNICEF (2010). Tracking public expenditure and assessing service quality in Early Childhood Development in South Africa. Accessed 21/August, 2014.

[15] Fleisch, B. (2008). Primary Education in crisis. Cape Town: Juta and Co.

[16] Flick, U. (2006). Triangulation in V. Jupp (Ed). The Sage Dictionary of Social Research Methods. London: Sage Publications.

[17] Gardner, R., \& Lambert, W. (1972). Attitudes and motivation in second language learning. Rowley, MA: Newbury House.

[18] Grant, C., and Osanloo, A. (2015). Understanding, selecting, and integrating a theoretical framework in dissertation research: Developing a 'blueprint' for your "house". Mexico: Unversity Press.

[19] Henning, E., Van Rensburg, W. \& Smit, B. (eds). (2009). Finding your way in qualitative research. Pretoria: Van Schaik.

[20] Howie, S., \& van Staden, S. (2012). South African Children's Reading Literacy Achievement - PIRLS and pre-PIRLS 2011 Summary of the key results (Media briefing). Pretoria: Centre for Evaluation and Assessment.

[21] Hungi, N, Makuwa, D, Ross, K, Saito, M, Dolata, F, Cappelle, S, Paviot, L \& Vellien, J. (2010). SACMEQ III Project Results: Pupil achievement results in reading and mathematics. Accessed on 9 October 2013 at [http://www.wd01-sacmeqiiiresultspupil]1-23.Index Mundi (2016). South Africa Demographics Profile, viewed October 24 2016, www.indexmundi.com/southafrica//demographicsprofile.html.

[22] Jadal M. M. (2012). Developing skills of English through remedial packages by low achievers at the primary level. Journal of Arts and Culture, 3 (2), 118-122.

[23] Johnson, B., \& Christensen, L. (2012). Educational Research (4th ed.). Los Angeles, CA: Sage.

[24] Kim, K. S. \& Sin, S. C. J. (2011). Selecting quality sources: Bridging the gap between the perception and use of information sources. Journal of Information Science, 37 (2), $182-192$

[25] Kristian, P. (2017). "Theory Building: Using Abductive Search Strategies." In Collaborative Research Design: Working with Business for Meaningful Findings. Per Vagn Freytag and Louise Young, editors. (Singapore: Springer Nature, 2018), pp. 45-71; Shepherd, Dean A. and Roy Suddaby. "Theory Building: A Review and Integration." Journal of Management 43 (2017): 59-86.

[26] Lerner, J. W., and Johns, B. H. (2014). Disabilities and Related Disabilities: Strategies for Success. Louis: National Louis University Press.

[27] Lesaux, N. K. (2017). Advancing learning opportunities for English learners: The next generation of research. New York: SAGA.

[28] Le Roux, M. C., Swartz, L., \& Swart, E. (2014). The effect of an animal-assisted reading program on the reading rate, accuracy, and comprehension of grade 3 children: A randomized controlled study. Child Youth Care Forum, 43, 655-673.

[29] Leki, I. (2014). Material, educational, and ideological challenges of teaching EFL writing at the turn of the century. International Journal of English Studies: Writing in the L2 classroom: Issues in pedagogy and research (197-209).

[30] Littlefield J. \& Cook, G. (eds). (2005). Child development: Principles and perspectives. Boston: Pearson

[31] Maree, K. (Ed). (2010). First Steps in Research. Pretoria: Van Schaik.

[32] Maree J. G (2012). Career adapt-abilities scale-South African form: Psychometric properties and construct validity. Journal of Vocational Behavior, 80 (3): 730-733. DOI: 10.1016/j.jvb.2012.01.005.

[33] McDonough, J., Shaw, C, and Masuhara, H. (2016). Materials and Methods in ELT: A Teacher's Guide 3rd Edition. Oxford: Willey- Blackwell.

[34] Mcdevitt, M. \& Ormrod, J. (eds). (2010). Child development and education. New Jersey: Pearson Education.

[35] Mertens, D. M. (2014, October). Issues for a better future: Transformative mixed methods research and cultural diversity, social justice, gender, and ethics. Korea: University Press. 
[36] Mishan, E. J. (2011). Pornography, Psychedelics, and Technology (Routledge Revivals): Essays on the Limits to Freedom. USA; Routledge.

[37] Mitchell, R \& Myles, F. (2004). Second language learning theories. Second edition. Great Britain: Hodder Headline Group.

[38] Mogi, K., \& Tokoro, M. (2014). Brain and creativity. Persian: Danjeh.

[39] Monteith, C. E., Brunner, M. E., Djagaeva, I., Bielecki, A. M., Deutsch, J. M., Saxton, W. M. (2016). A Mechanism for Cytoplasmic Streaming: Kinesin-Driven Alignment of Microtubules and Fast Fluid Flows. Biophys. J. 110 (9): 2053-2065 .

[40] Mpofu, S. (2017). Secukinumab sustains improvement in signs and symptoms of psoriatic arthritis: 2 year results from the phase 3 FUTURE 2 study. Oxford, England: SAGA.

[41] Mullis, I. V. S., \& Martin, M. O. (Eds.). (2015). PIRLS 2016 Assessment Framework (2nd ed). TIMSS \& PIRLS International Study Center, Boston College, Chestnut Hill, MA.

[42] Myers, B. R. 2012. "A Proposed Decision Rule for the Timing of Soccer Substitutions." Journal of Quantitative Analysis in Sports8: Article 9.

[43] Nieman, M. M. \& Monyai, R. B. 2006b. Preface. (In Nieman, M. M. \& Monyai, R, B., eds. The educator is a mediator of learning. Pretoria: Van Schaik. p. i-xv.).

[44] Nel, M., and Booysen, R. (2019). Exploring South African Foundation Phase teachers' understanding, skills, and training needs in the teaching of phonological awareness. Language Learning Journal. DOI: 10.1080/09571736.2019.1655585.

[45] Nel, J. A. (2011). Exploring the Personality Structure in the 11 Languages of South Africa. https://doi.org/10.1111/j.14676494.2011.00751.

[46] Ning, A. N., and Zhou, J, (2020). A predictive deep-learning approach for homogenization of auxetic kirigami metamaterials with randomly oriented cuts. Modern Physics Letters B. India: Xi'an Jiaotong University Press.

[47] Oliver, R. L. (2014), Satisfaction: A Behavioral Perspective on the Consume A Behavioral Perspective on the Consumer. New York: Routledge. DOI: 10.5901/MJSS.2013.V4N3P463.

[48] Pflepsen, A.,(2018). Relationships Between Coach Support and Teachers' Adoption of New Instructional Practices: Findings from the Nigeria Reading and Access Research Activity (RARA). Nigeria: SAGA. DOI: 10.3768/rtipress.2018.bk.0022.1809.6.

[49] Phajane, M. L., and Mokhele, M. L. (2013). Teaching Reading Skills in Home Language: A Case Study of Foundation Phase Teachers. Mediterranean journal of social sciences.

[50] Rajabi, S \& Ketabi, S. (2012). Aspects of cultural elements in prominent English textbooks for EFL setting. Theory and Practice in Language Studies 2 (4): 705712.

[51] Raymond, G. T., and Atherton, C. R. (1991). Blue Smoke and Mirrors: The Continuum in Social Work Education. Journal of $\begin{array}{llll}\text { social work education } 27 & \text { (3). DOI: }\end{array}$ 10.1080/10437797.1991.10672202.
[52] Reuters, T. (2011). The impact of research in primary care and family medicine: the Thomson Reuters Web of Science Subject Category 'Primary Health Care' Chris van Weel Family Practice, Volume 28, Issue 3, June 2011, Pages 239240.

[53] Richards-Tutor, C., Baker, D. L., Gersten, R., Baker, S. K., Smith, J. M., (2015). The effectiveness of reading interventions for English learners: a research synthesis. Except. Child. 1-26.

[54] Roche, T, Harrington, M (2013). Recognition vocabulary skills as a predictor of academic English performance and achievement in English. Language Testing in Asia 3 (12): 133144.

[55] Saez, A. (2010). Semi-structured Interview Protocol. Retrieved on 6 July 2011 from http://www.ehow.com/info7904390questions-intervieweeshould-ask-interview.html.

[56] Schofield, A. J. (2020). Object Narratives as a Methodology for Mitigating Marine Plastic Pollution: a New Multidisciplinary Approach, and a Case Study from Galápagos. London: Routledge.

[57] Schlebusch, S. (2008). Unlocking the growth potential. Randburg: Knowres Press.

[58] Shaw, A, and Masuhara, L. 2012). Materials development for language learning and teaching. Cambridge: University Press.

[59] Spaull, N., and Kotze, J. (2015). Starting behind and staying behind in South Africa. International Journal of Educational Development. DOI: 10.1016/j.ijedudev.2015.01.002.

[60] Taylor, S \& Coetzee, M. (2013). Mother-tongue classrooms give a better boost to English study later. Accessed on 3 January 2014 at [mg.co.za/article/2013-10-18- mother-tongueclassroomsgive-a-better-boost-to-english-studies-later]: 1-21.

[61] Trudell, B, Dowd, AJ, Piper, B \& Bloch, C. (2012). Early grade literacy in African Classrooms: Lessons learned and future directions. Working document. Tunisia: Association for the Development of Education in Africa.

[62] Van der Berg, S., Wills, G., Selkirk, R., Adams, C \& Van Wyk, C. (2019). The cost of repetition in South Africa," Stellenbosch University: SAGA.

[63] Vygotsky, L. S. (1978). Mind in society: The development of higher psychological processes. Cambridge, MA: Harvard University Press.

[64] Usherwood, S. (2019). Shooting the fox? UKIP's populism in the post-Brexit er. UK: University Press.

[65] Wilkinson, K. A. (2012). Predictive value of interferonrelease assays for incident active tuberculosis: a systematic review and meta-analysis. DOI: https://doi.org/10.1016/S1473-3099(11)70210-9.

[66] Zimmerman, L. \& Smit, B. (2014). Profiling classroom reading comprehension development practices from the PIRLS 2006 in South Africa. South African Journal of Education, 34 (3), 1-9. DOI: 10.15700/201409161101. 